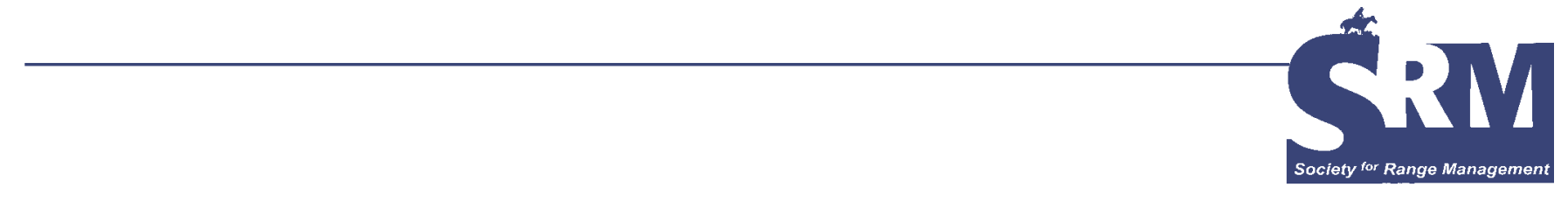

\title{
Climate Change Impacts on Australian Rangelands
}

\section{By C. J. Stokes, A. Ash, and S. M. Howden}

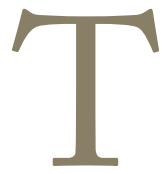

he recent Intergovernmental Panel on Climate Change (IPCC) Fourth Assessment report concluded that Australia has significant vulnerability to changes in temperature and rainfall projected under climate change. Agriculture and natural resources were two of the key sectors identified as likely to be strongly affected. Extensive grazing is by far the most widespread agricultural land use in Australia. Most of the country is unsuitable for intensive agricultural production and is used instead for low intensity production of beef and sheep (meat and wool). The grazing industry has been an important contributor to the overall economic growth of Australia, but has also been vulnerable to the impacts of a variable climate. Climate change will likely add to and exacerbate existing pastoral management challenges such as declines in pasture productivity, reduced forage quality, livestock heat stress, greater problems with some pests and weeds, more frequent droughts, more intense rainfall events, greater risks of soil erosion, and greater uncertainty about the future.

The native and improved pastures that form Australia's rangelands cover over three quarters of the continent (Fig. 1). For the purposes of this discussion we use a simple three-category classification of Australian rangelands: 1) the arid rangelands and deserts of the center; 2) the adjacent semiarid region, which includees the productive Mitchell Grass Downs to the northeast; and 3) the remaining more mesic rangelands consisting of the tropical savannas to the north and productive highly-modified pastures to the east. The most intensive cattle production systems are situated in the productive eastern rangelands, and generally use European cattle breeds (Bos taurus), whereas hardier breeds incorporating Bos indicus bloodlines tend to be used in the harsher tropical climates. Sheep grazing is largely restricted to the cooler southern rangelands. The diversity in the

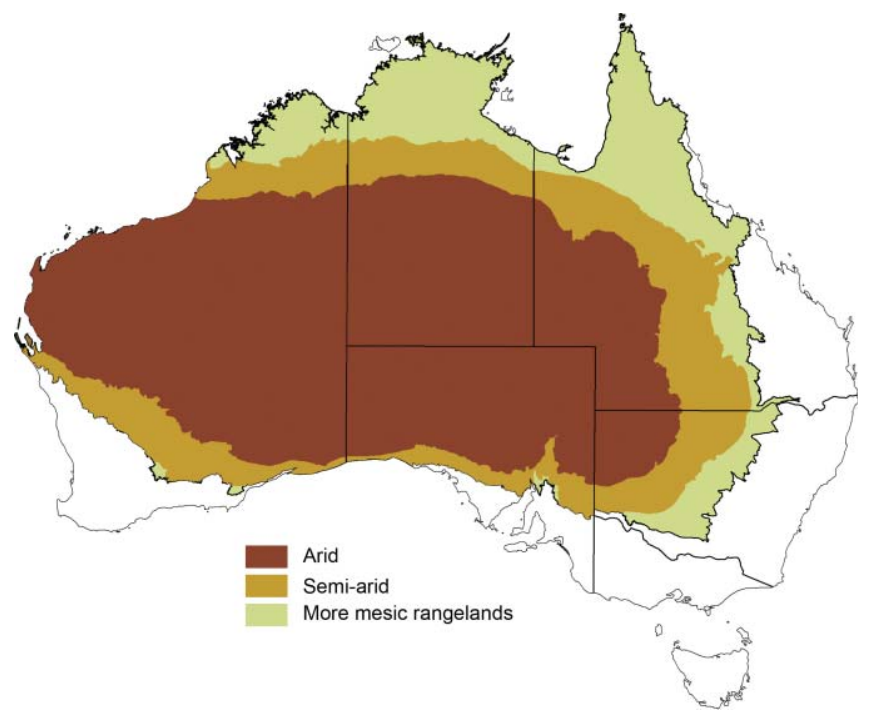

Figure 1. Classification of Australian rangelands based on a moisture index: arid (rainfall $<20 \%$ of potential evaporation $\left[\approx 250 \mathrm{~mm} \cdot \mathrm{yr}^{-1}\right]$ ), semi-arid (rainfall $=20-40 \%$ of potential evaporation $[\approx 250-350 \mathrm{~mm}$. $\left.\mathrm{yr}^{-1}\right]$ ), and remainder (rainfall $>40 \%$ potential evaporation $[\approx 350 \mathrm{~mm}$. $\left.\left.\mathrm{yr}^{-1}\right]\right)$.

rangelands means that there are likely to be regional and local differences in the effects of climate change.

In the following discussion, we summarize the range of likely impacts that climate change will have on Australia's rangelands and some of the implications of these changes.

\section{Climate Change Projections}

There is growing confidence that the Earth is warming and that future temperature increases and other climate changes at the global scale are highly likely. However, projections at regional and local scales, which are required for policy and 
land management planning, are more complicated and far less robust. Maps of "mean" climate change projections are useful to indicate that there will be spatial variation in climate change, but it is important to recognize that these "means" are not predictions and that there is considerable uncertainty in the range of projections for each point in space. Accordingly, it is essential that adaptation strategies take a flexible approach that considers the risks of the full range of projected possibilities (rather than assuming "mean" projections are necessarily representative at any particular point in space).

Temperatures in Australia are projected to increase by $1-5^{\circ} \mathrm{C}\left(1.8-9^{\circ} \mathrm{F}\right)$, depending on location and the emissions scenarios. The greatest warming is expected in the interior of the continent, particularly towards the northwest of the country (Fig. 2a). Associated with these temperature increases will be marked increase in the frequency of hot days and warm nights, but a less-marked decrease in the frequency of frosts.

Regional rainfall projections are less robust than temperature, and the range of uncertainty (10th-90th percentile) spans both drying and wetting trends at most locations in Australia. Median rainfall projections show a general pattern of drying across the continent that is strongest in the southwest. Drying trends are weaker in the east of the country, and the northern tropics are the least likely to experience declines in rainfall (Fig. 2b). Aside from changes in the amount of rainfall, there are also projected to be changes in seasonal rainfall distribution with reductions in winter and spring rainfall in the south. The intensity of rainfall is projected to increase in most parts of the country, particularly in the north, whereas the number of dry days will increase in many locations. Changes in the amount and distribution of rainfall and increases in evapotranspiration
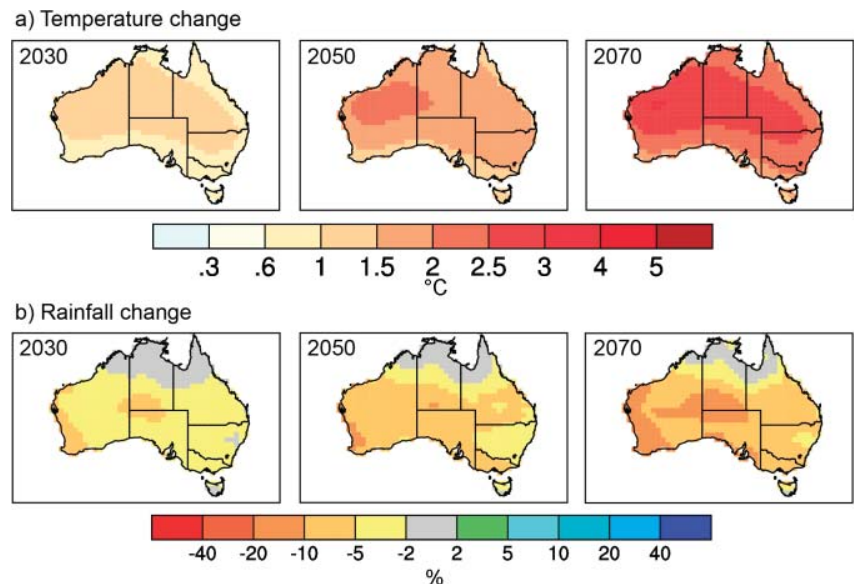

Figure 2. a, Median projections for changes in temperature in 2030 , 2050, and 2070 relative to the period 1980-1999. b. Median projections for changes in rainfall in 2030, 2050, and 2070 relative to the period 1980-1999. Based on A1B emissions scenario from the Intergovernmental Panel on Climate Change Special Report on Emission Scenarios (http://www.climatechangeinaustralia.gov.au). demand are projected to increase the incidence of drought with up to $40 \%$ more droughts in eastern Australia and $80 \%$ more in the southwest by 2070 . El Niño events could become drier in southeast Australia and La Niña events could become wetter, and changes in the Southern Annular Mode are projected to reduce rain across southwest Australia.

\section{Climate Change Impacts}

\section{Forage Production and Utilization}

The dominant influence of climate change on pasture growth is expected to be changes in the amount of rainfall. Furthermore, changes in the temporal distribution of rainfall could reduce the effectiveness of rainfall through projected increased variation within seasons (fewer, more intense rainfall events) and from year to year (more frequent droughts). Changes in river flow regimes and beneficial flooding could alter the production of locally-important ephemeral pastures on floodplains. Rising temperatures could benefit pastures in cooler southern climates by increasing the length of the growing season and reducing frost damage. However, increased plant growth in the cooler months could deplete soil moisture at the expense of subsequent pasture growth in the spring. Changes in seasonal patterns of forage availability could pose additional challenges for grazing management. In warmer climates, increased heat stress and increased evaporative demand would likely have negative effects on pastures.

The most certain aspect of global change is that atmospheric concentrations of carbon dioxide $\left(\mathrm{CO}_{2}\right)$ will increase and this will affect rangeland function even in the absence of climate changes (also see Morgan et al., p. 18-22). In water-limited rangelands, the dominant means by which $\mathrm{CO}_{2}$ will affect plant growth will be through changing patterns of plant water use. Indeed, experiments that have separated the components of $\mathrm{C}_{3}$ (cool season plants) pasture responses to $\mathrm{CO}_{2}$ have demonstrated that stimulated plant production was almost entirely attributable to indirect effects of moisture savings, rather than directly stimulated photosynthesis. Correspondingly there is growing evidence that $\mathrm{C}_{4}$ rangeland grasses (warm season grasses) might not be substantially less responsive to $\mathrm{CO}_{2}$ than $\mathrm{C}_{3}$ grasses, particularly under field conditions. The effect of $\mathrm{CO}_{2}$ in stimulating pasture growth could be greatest in ecosystems receiving intermediate amounts of rainfall (about 500$1000 \mathrm{~mm}$ or 20-40 inches annually, depending on latitude) where water is limiting during most periods of active plant growth.

There are strong interactions of vegetation responses to $\mathrm{CO}_{2}$ with other variables such as temperature, soil nutrients, and altered species interactions, so growth responses to $\mathrm{CO}_{2}$ might be variable. Modeling studies that have calculated "safe" livestock-carrying capacity from resource attributes and climate data have indicated that pasture growth is sensitive to small variations in climate, responses to rainfall 
are nonlinear, and there are interactions between the effects of $\mathrm{CO}_{2}$ and changing climate. For example, one study of Queensland native pastures found that the combined effects of warmer temperature, doubling $\mathrm{CO}_{2}$, and changes in rainfall of $-10 \%$ to $+10 \%$ altered "safe" carrying capacity by +3 to $+45 \%$.

The more productive northern and eastern rangelands are the most likely to provide opportunities for slight increases in productivity in the future. The northern rangelands are the only area of the country where median rainfall is not projected to decline with climate change, and the proximity to the coast should moderate increases in temperature slightly (Fig. 2). In the eastern rangelands there is projected to be some drying and increase in the frequency of droughts, but moderate amounts of warming might benefit pasture growth by extending the growing season, so that there is projected to be a slight net increase in pasture productivity. In contrast, changes in rainfall and temperature are both projected to have their greatest negative impacts in the central arid rangelands (Fig. 2), where already-marginal enterprises could be at most risk of becoming nonviable under climate change.

Stimulation of forage production by $\mathrm{CO}_{2}$ is associated with changes in forage quality through declines in forage protein content, and increased forage nonstructural carbohydrates and decreased digestibility of tropical grasses. Warmer conditions tend to significantly decrease nonstructural carbohydrate concentrations (and digestibility in tropical species), while also slightly reducing leaf $\mathrm{N}$ content. However, in counteracting this general overall tendency to reduced forage quality, there might be seasonal improvements in forage quality in which growth seasons are extended either by earlier onset of winter growth or prolonged availability of soil moisture (and delayed grass senescence) as a result of $\mathrm{CO}_{2}$-induced conservation of water by grasses. The combined effects of rising $\mathrm{CO}_{2}$ and temperature will modify seasonal patterns of variation in forage protein and utilizable energy with likely consequences for ruminant nutrition, but these effects have yet to be investigated.

\section{Botanical Change in Vegetation Composition}

The likelihood of climate change affecting the botanical composition of pastures is demonstrated by the past role weather events have played in affecting species changes. Where climates become hotter and drier, pasture composition is likely to shift to more xeric species that could be less suitable for grazing. Grazing management practices might have to change to match the new vegetation and climate. Further changes in rangeland vegetation are expected in response to rising atmospheric $\mathrm{CO}_{2}$ concentration. Rising $\mathrm{CO}_{2}$ will affect pastures by changing the temporal and spatial patterns of soil moisture availability: higher levels of $\mathrm{CO}_{2}$ delay soil moisture depletion following rainfall events, thereby increasing the availability of moisture deeper in the soil profile. Differences in species responses to $\mathrm{CO}_{2}$ are therefore likely to be strongly influenced by differences in rooting patterns and the ability of plants to rapidly exploit conserved soil moisture from reduced transpiration of other plants. Deep-rooted woody plants and legumes are likely to be advantaged over grasses at higher $\mathrm{CO}_{2}$ levels, both because of higher $\mathrm{CO}_{2}$-sensitivity of growth and because of the ability to tap deep water while still competing with grasses for moisture in shallow soil layers. Changes in fire regimes would also be expected to affect the balance between woody and herbaceous species in savannas and other rangelands where these growth forms co-occur.

\section{Fire}

A dominant feature shaping the ecosystems of Australia, and particularly the tropical rangelands, is fire. This long history of burning has resulted in plants and soils relatively adapted to frequent fire, especially in the tropical zones. In the more temperate zones, fire has been less of a historical influence. Climate change could affect fire regimes in several ways. First, any changes in pasture production (discussed above) will affect fuel loads, unless utilization levels by livestock are adjusted to match changes in grass growth. Second, pastures could cure earlier under warmer climates, shifting the timing of fires to earlier in the season, and increasing the potential for more intense fires later in the season. Third, hotter and drier conditions could increase the risk of wild fires and make prescribed burns more difficult to manage. Finally, if increases in year-to-year rainfall variability are accompanied by similar increases in variation of fuel loads, then fire regimes could shift toward fewer, more intense fires, particularly in the northern tropical pastures.

\section{Other Climate-Driven Influences on Rangelands}

A major risk to the grazing industry from climate change relates to the potential change in the distribution of pests, feral animals, diseases, and weeds, particularly a southward range shift of tropical pests (e.g., ticks, flies, and tropical weeds) following warming conditions. Australian researchers have placed a high priority on developing tools to predict the change of extent and impact of pest species.

Projected increases in rainfall intensity are also likely to increase the risks of soil erosion. This will likely be exacerbated by increased year-to-year variability in rainfall, with more droughts and more floods, and therefore result in a greater chance of erosion events when a wet year follows a drought (when protective plant cover is low). Although Australian rangeland productivity is comparable to other rangelands of the world, aerial and basal cover can be quite low, increasing the risks of erosion.

Climate change will substantially increase the frequency of heat stress days, particularly in northern Australia, reducing productivity, decreasing reproductive rates, and increasing concerns about animal welfare in locations where grazing populations are concentrated, such as feedlots. The upward trend in animal numbers in Australia has been made 
Table 1. Industry and policy-level activities for adapting rangelands to global change (from Howden et al. 2003)

Policy: Develop linkages to existing government policies and initiatives (e.g., policies on greenhouse sinks, natural resource management, water resource allocation, rural development, poverty alleviation), and into integrated catchment management so as to enhance resilience to climate change.

Managing transitions: Create policies and mechanisms to provide technical and financial support during transitions to new systems that are more adapted to the emerging climate.

Communication: Ensure communication of broader climate change information as well as industry-specific and regionspecific information as it becomes available.

Climate data and monitoring: Maintain effective climate data collection, distribution, and analysis systems to link into ongoing evaluation and adaptation. Monitor climate conditions and relate these to forage yield and quality and biodiversity aspects to support/facilitate adaptive management. Develop climate projections that can be downscaled so as to be relevant to farm and catchment scale.

Research and Development (R\&D) and training: Undertake further adaptation studies that include broad-based costs and benefits to inform policy decisions. Maintain the research and development base (people, skills, institutions) to enable ongoing evaluation of climate/ $\mathrm{CO}_{2} /$ (species or landuse)/management relationships, and to streamline rapid R\&D responses (for example, to evaluate new adaptations or new climate change scenarios). This R\&D needs to be developed in a participatory way so that it can contribute to training to improve self-reliance in the agricultural sector and to provide the knowledge base for farm-scale adaptation.

Breeding and selection: Maintain public sector support for agricultural biotechnology and conventional breeding with access to global gene pools so as to have suitable options for higher temperature regimes and changed moisture availability and possibly more climate variability.

Model development and application: Develop further grazing systems modeling capabilities that link with meteorological data distribution services and can use projections of climate and $\mathrm{CO}_{2}$ levels, natural resource status, and management options to provide quantitative approaches to risk management for use in several of these cross-industry adaptation issues (e.g., AussieGrass). These models have been the basis for successful development of participatory research approaches that enable access to climate data and interpretation of the data in relation to farmers' own records and analysis of alternative management options. Such models can assist proactive decision making on-farm, and inform policy, and can extend findings from individual sites to large areas.

Seasonal forecasting: Facilitate the adoption of seasonal climate forecasts (e.g., those based on El Niño and La Niña, sea-surface temperatures, etc.) to help farmers, industry, and policy incrementally adapt to climate change while managing for climate variability. Maximize the usefulness of forecasts by combining them with on-ground measurements (i.e., soil moisture, standing forage), market information, and systems modeling.

Pests, diseases, and weeds: Maintain or improve quarantine capabilities, sentinel monitoring programs, and commitment to identification and management of pests, diseases, and weed threats. Improve the effectiveness of pest, disease, and weed management practices through predictive tools such as quantitative models, integrated pest management, area-wide pest management, and routine record-keeping of climate and pest/disease/weed threat, and through development of resistant species and improved management practices.

Water: Increase water use efficiency by 1) using a combination of policy settings that encourage development of effective water-trading systems that allow for climate variability and climate change and that support development of related information networks, 2) improving water distribution systems to reduce leakage and evaporation, and 3) developing farmer expertise in water management tools and enhancing adoption of appropriate water-saving technologies.

Landuse change and diversification: Undertake risk assessments to evaluate needs and opportunities for changing species, management, or landuse/location in response to climate trends or climate projections. Support assessments of the benefits (and costs) of diversifying farm enterprises.

Natural resource base: Determine the impact of climate change (interacting with land management) on natural resource degradation issues such as erosion and salinization risks and inform policymakers. 
possible by continued breeding improvement in livestock, especially drought resistance in sheep and cattle, and resistance to pests and diseases. As conditions in southern regions become harsher, pastoralists will have to rely on hardier northern breeds (and crosses), but this likely will come at the cost of lower productivity, fecundity, and meat quality.

\section{Management and Policy Implications}

Climate change will involve not only negative impacts for Australian rangelands, but also some benefits. Although some regions will be worse off, there will opportunities for improved production in others. However, minimizing the negative impacts and maximizing the benefits will require responses at both policy/industry level (Table 1 ) and the individual property scale (Table 2). Engaging pastoralists and policy makers during the evaluation of climate change impacts and development of adaptation options will assist in directing efforts that are most likely to be appropriate, effective, and adopted.

Given the uncertainty in regional and property-scale impacts of climate change, adaptation strategies will need to take a flexible, risk-based approach that develops options and capacity to cope with a range of possible local climate changes, and continually monitor responses to ensure that they are appropriate and remain effective. For example, one important recommendation will be increased adoption of climate forecasting strategies. Adjusting stocking rates to seasonal variation in forage production will build in some automatic tracking of trends in climate change. Many of the options that provide gradual adaptations are similar to management adjustments that pastoralists routinely make in tracking market and technology trends and are likely to occur with little intervention beyond support for research and extension. However, it will also be important to determine where such gradual, incremental changes will be insufficient. Where either the magnitude or rate of change imposed exceeds the adaptive capacity of pastoralists, more intensive policy intervention or industry change might be required.

Biodiversity in rangelands will also have to be managed under climate change, but adaptation options are currently mostly speculative. Protected areas might have to be reconfigured, with greater emphasis on facilitating shifts in native species distributions, restricting exotic invasions, and maintaining refuges. Conservation management activities might need to include "matrix lands" between protected areas. Even if a landscape can be designed to be "permeable" to migrating species, the rate of climate change is likely to exceed the dispersal rate of all but the most mobile organisms (e.g., leading to the likelihood of more weeds). Some form of assisted dispersal is likely to be necessary, but this raises various issues of ethics, management, and cost-effectiveness.

In developing sound climate change adaptation strategies it will be important to continually ensure that responses are effective in achieving their intended benefits while minimizing unintended consequences. There are several foreseeable risks of maladaptation, where trade-offs will need to be carefully evaluated. For example, introducing legumes into

\section{Table 2. Farm level adaptations to global change (from Howden et al. 2003)}

\section{Managing pasture productivity and grazing pressure}

Selection of sown pastures better adapted to higher temperatures and water constraints

Provision of additional nitrogen through sown legumes

Provision of phosphates to both improved and unimproved pasture

Provision of urea and phosphates directly to stock via reticulation

Greater utilization of strategic spelling (deferment)

Introduction of responsive stocking rate strategies based on seasonal climate forecasting

Development of regional safe carrying capacities (i.e., constant conservative stocking rate)

Where appropriate, development of software to assist proactive decision-making at the farm scale

\section{Managing pests, disease, and weeds}

Improvement of pest predictive tools and indicators

Improvement of quantitative modeling of individual pests to identify appropriate time to introduce controls

Increased (but cautious) use of biological and other controls

Increased use of insect traps for sentinel monitoring and for population control

Incorporation of alternative chemical and mechanical methods for reducing woody weeds

Acceptance that the biota might change

\section{Animal husbandry and managing health}

Selection of animal lines that are resistant to higher temperatures

Modified timing of mating based on seasonal conditions

Modified timing of supplementation and weaning

Construction of shading and spraying facilities

Increased use of trees for shading and reducing wind erosion 
native pastures could offset declines in forage quality, but incurs the risks of soil acidification and impacts on biodiversity. Likewise, carbon trading schemes can create shortterm opportunities for earning carbon credits from increases in woody plant biomass, but this would have to be weighed against the ongoing costs of possible losses in pasture production or reduced water yields from catchments (also see de Stieguer et al., 7-11). At the government and institutional level, it will be important to incorporate considerations of climate change adaptation into new and existing policies and initiatives to ensure complementarities and reduce conflicts in policy goals.

Successful adaptation will require a mix of pre-emptive and reactive adaptive strategies that respond to the combined changing challenges and opportunities posed by climate change and other social, economic, and institutional pressures. Adoption of new property management practices will require 1) confidence that climate change can be separated from the naturally high year-to-year climate variability inherent in these production systems; 2) the motivation to change based on the perceived risk and opportunities of climate change; 3) establishment and implementation of applicable new technologies and demonstration of their benefits; 4) buffering against establishment failure of new practices during less favorable climate periods; 5) alteration of transport and market infrastructure to support altered production; and 6) development and modification of government policies and institutions to support adoption and implementation of the required changes. Adaptation strategies that incorporate the above considerations are more likely to be of value, as they will be more readily incorporated into existing on-farm management strategies.

\section{Additional Reading}

Campbell, B. D., D. M. S. Smith, and G. M. McKeon. 1997. Elevated $\mathrm{CO}_{2}$ and water supply interactions in grasslands: a pastures and rangelands management perspective. Global Change Biology 3:177-187.

Crimp, S. J., N. R. Flood, J. O. Carter, J. P. Conroy, and G. M. McKeon. 2002. Evaluation of the potential impacts of climate change on native pasture production: implications for livestock carrying capacity. Final Report to the Australian Greenhouse ffice. Available at: http://www.climatechange.gov. au/publications/index.html. Accessed 1 March 2008.

CSIRO. 2007. Climate change in Australia: technical report. Available at: http://www.csiro.au/resources/ps3j6.html. Accessed 1 March 2008.
Gifford, R., B. D. Campbell, and S. M. Howden. 1996. Options for adapting agriculture to climate change: Australian and New Zealand examples. In: W. Bouma, G. I. Pearman, and M. R. Manning [EDS.]. Greenhouse: coping with climate change. Melbourne, Australia: CSIRO. p. 399-416.

Hall, W. B., G. M. McKeon, J. O. Carter, K. A. Day, S. M. Howden, J. C. Scanlan, P. W. Johnston, and W. H. Burrows. 1998. Climate change in Queensland's grazing lands: II. An assessment of the impact on animal production from native pastures. The Rangeland Journal 20:177-205.

Hennessy, K., B. Fitzharris, B. C. Bates, N. Harvey, S. M. Howden, L. S. J. Hughes, and R. Warrick. 2007. Australia and New Zealand. In: M. L. Parry, O. F. Canziani, J. P. Palutikof, P. J. van der Linden, and C. E. Hanson [eds.]. Climate change 2007: impacts, adaptation and vulnerability. Contribution of Working Group II to the Fourth Assessment Report of the International Panel on Climate Change. Cambridge, United Kingdom: Cambridge University Press. p. 507-540.

Howden, S. M., A. Ash, S. Barlow, T. Вooth, S. Charles, R. Cechet, S. Crimp, R. Gifford, K. Hennessy, R. Jones, R. Kirschbaum, G. M McKeon, H. Meinke, S. Park, B. Sutherst, L. Webb, and P. Whetton. 2003. An overview of the adaptive capacity of the Australian agricultural sector to climate change: options, costs and benefits. Canberra, Australia: CSIRO Sustainable Ecosystems. Available at: http://www.cse. csiro.au/publications/2003/AGOAgClimateAdaptationReport. pdf. Accessed 1 March 2008.

McKeon, G. M., And S. M. Howden. 1992. Adapting the management of Queensland's grazing systems to climate change. In: S. Burgin [ED.]. Climate change: implications for natural resource conservation. University of Western Sydney Occasional Papers in Biological Sciences No 1. Sydney, Australia: University of Western Sydney. p. 123-140.

McKeon, G. M., S. M. Howden, N. O. J. Abel, and J. M. King. 1993. Climate change: adapting tropical and subtropical grasslands. In: M. J. Baker [ED.]. Grasslands for our world. Wellington, New Zealand: SIR Publishing. p. 426-435.

Stokes, C. J., AND A. J. Ash. 2006. Special example 1: Impacts of climate change on marginal tropical animal production systems. In: P. C. D. Newton, R. A. Carran, G. R. Edwards, and P. A. Niklaus [EDs.]. Agroecosystems in a changing climate. London, United Kingdom: CRC Press. p. 323-328.

Authors are Senior Research Scientist, CSIRO Sustainable Ecosystems, PMB, PO Aitkenvale, O 4814, Australia, Chris. Stokes@csiro.au (Stokes); Senior Principle Research Scientist, CSIRO Sustainable Ecosystems, 306 Carrmody Rd, St Lucia, Q 4067, Australia (Ash); and Flagship Director, CSIRO Climate Adaptation Flagship, GPO Box 284, Canberra, ACT 2602, Australia (Howden). 